By FREMONT RIDER

\title{
Progress in Microprint:
}

\section{Part I. Microcards ${ }^{1}$-The Next Steps}

W

HEN ONE is asked what, on the whole, has been the reception of the microcard idea-whether librarians and scholars, generally speaking, have approved or disapproved of it-the answer in brief must be that they have approved. To be more specific, however, the comments received have grouped themselves into three classes:

I. Unquestioningly enthusiastic acceptance - "unquestioning" because it was an acceptance unaware of the number of practical problems that have still to be solved before microcards can become a reality and of the extremely puzzling complexity of some of these problems. This sort of acceptance might be summarized in some such phraseology as: "Microcards sound wonderful; we'd like to buy some at once. When will they be ready?"

2. Understanding acceptance- "understanding" because, although often just as enthusiastic as " $I$," it was tempered with an appreciation of the difficulties mentioned, sometimes so much tempered that it approached grave caution. This sort of acceptance might be summarized in some such phraseology as: "Although revolutionary, microcards do seem a most promising suggestion. We hope to surmount the serious difficulties involved."

3. Denial of acceptance-that is, a belief either that microcards are not realizable or, if realizable, that they would be valueless. So far, out of all of the hundreds of letters and reviews, just one has fallen into this class.

${ }^{1}$ At its first session the Microcard Committee formally voted to approve library use of the word "microcard," which I proposed as the name of the new concept to which I applied it, viz., a standard size catalog card, having on its back a micro-text of the item cataloged on its front; but they recommended that its form, as I had used it, be amended to one without a hyphen.
The other outstanding fact about the reception of the microcard idea has been that, on the whole, scholars have been more enthusiastically in favor of it than librarians-perhaps, it is true, because they were less aware of the aforesaid difficulties.

Of course all this encouragement has been of itself helpful, and when-as was often the case-it was conjoined with some practical suggestion, it was doubly helpful. As was to be expected, there were, even in the favorable comments, scattered criticisms.

First, and most common of all, has been one that was really based on a misreading of text of The Scholar and the Future of the Research Library. At least a half-dozen readers, who happened to be personally familiar with micro-techniques, were positive that five hundred pages of an ordinary book could not be gotten on the back of a catalog card. What happened here was that they were so dazzled by what the book said ought to be eventual future possibilities that they overlooked what it called the realizable present. This point was further discussed in College and Research Libraries (March I945, p. I8o-8I).

\section{The Subject Heading Problem}

The criticism next in order of mention struck at the point where The Scholar... itself admitted that it was vulnerable, i.e., the suggestions which it made for microcard subject headings. Fortunately, since the 
book came out, a novel and extremely valuable suggestion on this point has been offered by members of the cataloging staff of the Library of Congress.

Their suggestion in brief is:

a. That all microcards have classified subject headings, not alphabetical ones

b. That the classified arrangement be according to either the Dewey Decimal or the Library of Congress classification, at the option of each library

c. That the subject approach be shown by the classification symbols of each classification, which are to be printed on every microcard, in the two upper corners-D.C. on the left, L.C. on the right

d. That, on a line between the two, there be given a translation, in words, of the meaning of the symbols

e. That, however, this translation line be an explanatory line only, without filing value, all filing being done, in classification order, by means of the symbols

f. That all microcard-holding libraries be supplied with an alphabetical "relative index" on cards, affording their users a key to the classification used, to aid them in finding their subject if they are unfamiliar with its classification position.

At a recent meeting the Microcard Committee discussed this problem of the subject approach to microcards at great length. It unanimously approved the above Library of Congress solution, but at the same time it pointed out that it needed a further modification, or amplification, if microcard subject headings were to be of practical value in those numerous places in every classification where a classification symbol alone is quite inadequate. (Biography is one such very obvious place; individual names of persons, places, or things under all the "other" or " 9 " headings in the Dewey Classification are another example; the names of individual towns and cities under state or county symbols in geography and local history are still another.) So the committee added these two important additional paragraphs: g. In cases (as in biography, local history, geography, etc.) where the subject approach demands a specific proper name (or, in a few cases, a specific common noun), this specific name subhead shall be made an integral part of the subject heading, being placed between the two classification symbols, set in their type, and used as a definite part of each of them

h. This proper name, subclassificational heading word is to be a filable part of the subject heading, all cards bearing such words to be arranged alphabetically under the subject symbol of which they are a part. (The explanatory, nonfiled phrase will also still appear on the same line, but it will be set. in a smaller, and quite different, type; and, in the case of these "compound" subject headings, it will follow the subclassification word.)

Two sample microcards showing the proposed regular and "compound" classificational subject heading forms appear on the following page.

There still remains the question as to how microcards are to be subfiled under any given subject heading, whether that heading be a regular or a compound one. It had been suggested in the committee's "agenda" that this subfiling under subject be, not by author (as is now customary), but by the date (year of publication) of the item. This was suggested for four reasons: (I) the date is generally easy to ascertain; (2) it is a symbol easy to indicate on the cards (possibly even as a suffix to the classification symbols) ; ( 3 ) it is easy for users to understand and is brief; and, finally and most important of all, (4) it segregates the material under a given subject in accordance with its recency.

But the members of the Microcard Committee on the whole disagreed with this agenda suggestion; they considered it too sweeping. Although they recognized the value of a subfiling by date in the case of certain subjects, and in fact for many subjects, they felt that for other subjects 


\section{Levine, IsAac Don, 1892 -}

Mitchell, pioneer of air power... New York, Duell, Sloan and Pearce [1943]. (viii p., 2 l., 420p. front., ports., 22cm. - "Mitchell's own writings: $p$. 401-5)

[2d of 4--p. 110-214]

"Only the significant and influential events of Mitchell's early life are portrayed, and the emphasis of the study is on his public life, with, however, more of his personal life and characteristics than were given in Gauvreau and Cohen... This is also more carefully organized and written than the earlier book." - A.L.A. Booklist.

275.1

$$
\text { Missions - China }
$$

\section{Hodgkin, Henri Theodore, 1877 -}

Living issues in China and the possible direction of their solution... New York, Friendship press [1932]. (viii, 215p. double map. 19cm. - Reading list: $p$. [204]-10.)

[1 st of 2-p. i-viii, 1.96]

Discusses China's government, educational system, social organization, economic conditions, health problems, international relations and religion, and how Christian missionaries can help in solving her problems. Author, a medical missionary in China, 1905-10, served ten years as secretary of the Friends' Foreign Mission Assoc. and seven as secretary of the National Christian Council of China, traveling through China in its interests. He has written several books on religion, especially on its missionary aspect.

W'esleyan University Library

subfiling by author is more useful.

They unanimously agreed, however-and this is very important-that this last conclusion did not involve, for microcards, any necessity whatever for introducing Cutter author numbers into the classification symbols-simply because, as was pointed out in The Scholar ..., the Cutter numbers were originally worked out for call numbers, i.e., for a shorthand device to letter on the backstrips of books. On microcards we do not need any such shorthand device, for we have the author's full name, given where it is immediately available, i.e., on the line immediately below our subject classification line. We can, therefore, in the subject 
catalog, automatically subfile the entries by it. Eliminating all Cutter numbers saves work, renders the filing system clearer to users (who never do understand the Cutter symbolization), and renders uniformity in the entire subject approach easily possible.

But subfiling by date was by no means ruled out by the committee, and it is automatically available as an alternative, for the date of issuance is also shown in the catalog entry; and, to make it stand out and so more easily usable in filing, if desired, the committee proposed to set it, like the subject heading, in boldface type. In other words, each library is given a considerable choice of subject filing arangements, but it is given all of them while using exactly the same microcards and using them without having to make any changes or additional markings.

\section{The Scholar ... Not Optimistic Enough}

A considerable number of correspondents and reviewers charged that The Scholar... gravely underestimated the importance of the microcard proposal and underestimated it in two quite different directions.

On the one hand were those who insisted that it had said altogether too little about the possibilities offered for original publication in microcard form. It did, of course, refer to these possibilities, and at some length ${ }^{2}$ but it is true that it concerned itself mostly with the microcarding of already printed material.

Nevertheless, let me repeat here that I entirely agree that, for vast areas of material, original publication in microcard form is clearly indicated; for in no other possible way can the results of one's research be brought so easily and so cheaply to the attention of one's colleagues in one's subject field. Practically nothing is required for microcard publication except a clean typing

\footnotetext{
2 Rider, Fremont. The Scholar and the Future of the Research Library. New York City, Hadham Press, 1944, p. 204-05, 2 16-19.
}

of one's article, pamphlet, book, or thesisalthough, of course, the more carefully it is typed the better. Furthermore, photographs, drawings, and graphs can be automatically included in one's microcard text, at no additional cost whatsoever.

Finally, besides all these advantages at the author's end, there is, at the user's end, the fact that with microcards of hitherto unpublished material, as with all other microcards, we have an item already fully and carefully cataloged, an item already bound and completely ready for an almost automatic filing and one which, when it has been filed, occupies little space. One finds that scholars are strongly inclined to see in this use of microcards one of the most intriguing possibilities.

Good-natured criticism of quite a different sort came from those numerous correspondents and reviewers who insisted that even the title of The Scholar and the Future of the Research Library was all wrong! They said that, in continually emphasizing the value of microcards to "research" libraries, it slurred over even a broader and more important field of usefulness for them. In his well-phrased review in the A.L.A. Bulletin, ${ }^{3}$ Clarence S. Paine, of Beloit College, phrases this criticism in these words: "There are ... more positive implications for the library of the small undergraduate college ... [than for research libraries]. There is little doubt that the microcard even more than microfilm presents an opportunity for the small college to acquire vast amounts of original source materials-materials which are not now available to them." And Mr. Paine adds why it does: “... if, by the adoption of ... the microcard plan the smaller libraries can reduce the cataloging, binding, and storage costs ... of research materials by more than 90 per cent, funds

3 Paine, Clarence S. "The Administrator's Viewpoint." A.L.A. Bulletin 38:455-56, November 1944. 
will be available for the purchase of a significant number of microcard titles."

Other librarians of small colleges have seen the same point. They have seen the microcard's saving in first cost and expensive research materials at last brought within their easy financial reach; but they have also seen the savings beyond the first cost (saving that microfilm-and microprint in other than microcard form-did not, and could not, offer), i.e., the elimination of cataloging cost and storage cost. I had not originally expected very heavy sales of The Scholar ... to small libraries; but hundreds of their librarians have bought it and are still buying it and, judging from their resultant letters, have been reading it with avidity. Now their prevailing mood seems to be one of anticipation: "When will we be able to buy microcards?"

\section{The Space-Saving Aspect of Microcards}

On the whole The Scholar... tended, perhaps, to stress the space-saving advantages; Mr. Paine, on the other hand, stresses their savings in first cost. In discussing their issuance and use over these last nine months I have come to the conclusion that it is their first-cost saving that, with most librarians, is going to be their primary appeal; and that their space-saving advantages, although admitted, will not immediately be compelling enough to lead to action. In other words, I am inclined to think that librarians are not going-at least not in the near future-to buy microcards mainly to save shelf space. Eventually, if microcards fulfil their promise, they will do this, but not until space pressure occurs.

This conclusion was brought home to me by a colloquy that developed at one of the sessions of the Microcard Committee. We were discussing certain specific titles and categories of material as samples which might be selected to initiate microcard publi- cation. In the course of the discussion, one of the members remarked: "We shall have to try, so far as we can, to see that the libraries select for microcarding only material that is going to be really used; otherwise, they may clutter us up with a lot of microcard junk."

Now, from one point of view, this is a natural, reasonable, and justifiable comment. Particularly is it justifiable when we are trying to start microcard development and to educate our library clientele in the practical use of microcards.

But, if we look at our research library problem from a long-range standpoint, it can be very plausibly argued that exactly the reverse of this warning would be even more justifiable, viz., that much-used material is exactly the material that should not be microcarded, simply because, after all, in the . present state of our techniques at least, material is more easily usable in book than in microcard form. In other words, it is the seldom-used items that we ought to be microcarding, and this means much very common material. Why will microcarding eventually concentrate on this sort of material? Primarily to save the storage space that it now takes up in many libraries in its present book form.

The best way to prove the point of this last paragraph is to cite a specific example. Take that classic two-volume standby, Stanley's In Darkest Africa, the undisposable leftover of practically every odd lot of library duplicates! Not once in five years will anyone come along to take your copy off the shelves. In other words, here is a title that comes pretty closely to the "junk" category. Yet, can any real research library afford to throw it away entirely? Trivially common in money value though it is, littleused though it is, it still remains a great classic of exploration and still may be referred to for information on African native life. It 
still has some biographical value and may even have some interest to an investigator into the aggressive publishing methods of the late Victorian period! No, we can't throw it away. Yet its two fairly fat volumes cost-at least they do on Wesleyan's shelves -nearly two cents a year just to keep and store. On the other hand, reduced to microcard form (if and when it is out of copyright, of course), In Darkest Africa would still be available to those few who wanted it and at a saving in storage cost which would, in a very few years indeed, fully amortize its microcard cost, leaving thereafter practically no storage cost whatever.

\section{Possible Revisions of Filming Technique}

The phrasing used in The Scholar... in referring to the two copies of a text required for microcard photographing seems also to have been somewhat misleading. The Scholar... said that these two copies were "of course destroyed" in this photographing process and that therefore the "sponsoring" library supplying them would probably want to have a third copy so that at least one library in the country - and this naturally the sponsoring library in the field -would have it available in its original book form to serve those researchers for whom microcard copies of it were, for some very special reason, not sufficient.

It is true that, if we use the close-trim, spread-layout technique suggested in The Scholar..., the two copies used in microcard photographing are "destroyed" as bound books. But it is also true that they can be reassembled again, after photographing, in the form of closely trimmed, but still textually intact, loose sheets, and that, if they are properly preserved in this form, they will still be usable by any researcher who wants the original book text. Also, of course, they constitute insurance in case remicrophotographing is necessary.

Vernon D. Tate points out to me that the rubber cementing of the cropped pages, which was suggested in The Scholar..., involving, as it would, the necessity of removing the cement when the pages are reassembled afterward, can be eliminated. $\mathrm{He}$ states that even now vacuum copy holders (keeping copy in place by pneumatic pressure) are available, large enough to take a considerable number of laid-out pages. This fact simplifies the whole process and greatly lessens the possibility of real book destruction-so much so that I now rather doubt the necessity of a sponsoring library's burdening itself with the cost, and the cost of storage, of a third copy.

Since The Scholar . . . appeared I have also done some further experimenting with the photographing of single copy, uncropped material. By using $16 \mathrm{~mm}$., instead of $35 \mathrm{~mm}$., film, by running double-page "openings" lengthwise of the film instead of across it (so that the finished pages will read in correct order across the microcard), by closing up on "frames" so as to eliminate film waste on outside page margins, and then by stripping successive lengths of the resulting $16 \mathrm{~mm}$. film lengthwise across the back of the microcard, I find it is easily possible to get about fifty ordinary book pages on one card. Fifty pages, in other words, by following what might be termed "conventional" microphotographing methods, or at least methods which use only one copy of the text and do not destroy it at all. Of course fifty pages are not one hundred pages, but in many cases the item being photographed does not run to more than fifty pages, while, in many other cases, it may be a unique item, or at least one so valuable that the mutilation of it is out of the question. This conventional page-by-page photographing technique is, of course, slower (so far as camera time is concerned), but the extra expense is more than offset in the case of expensive items by the saving in book cost. The present main objection to 
cards made by this method is that, although perfectly readable, they look "messy." ought, however, to be possible to eliminate this and, in any event, it is good to know that by this very slight modification indeed of our ordinary past photographic practice a fairly efficient - and, in many cases, an adequately efficient - use of our available microcard space can be obtained.

\section{Microcard Committee}

The next step in the practical development of the microcard concept was, The Scholar . . . urged, the appointment of a representative committee of librarians which might advise concerning that development and coordinate it. In the initial work of securing the appointment of this committee the sympathetic cooperation of Archibald MacLeish was invaluable, even though in the middle of it he was abruptly translated to a broader-but no librarian will admit a higher-sphere of usefulness. When he left the Library of Congress four members had already been appointed to the committee. Here is the complete Microcard Committee as it was constituted when it held its first meetings in New York January 23, 24, and 25 last:

Keyes D. Metcalf, director, Harvard University Libraries, appointed by the Association of Research Libraries

Paul North Rice, reference librarian, New York Public Library, appointed by the American Library Association

John W. Cronin, assistant director, Processing Department, Library of Congress, appointed by the Librarian of Congress

Mrs. Winifred Gregory Gerould, formerly editor of the Union List of Serials, etc., appointed by the Bibliographical Society of America

Oliver W. Holmes, program adviser, National Archives, Washington, D.C., appointed

4 Lt. Tate comments on this: "The 'messy' appearance of the photographic microcard can probably be eliminated by proper technique, possibly including the mounting of the strips on a glass plate before the card is printed." by the Archivist of the U.S. and the Society of American Archivists

Frederick C. Hicks, librarian, Yale Law School Library, asked to serve as an unofficial representative of the professional library group

Mary A. Bennett, supervisor, Binding Department and Photograph Division, Columbia University Libraries, appointed by the Special Libraries Association

Charles F. Gosnell, librarian, Queens College Library, and associate in the School of Library Service, Columbia University, appointed by the Association of College and Reference Libraries

Fremont Rider, librarian, Wesleyan University Library.

Vernon D. Tate, editor of the Journal of Documentary Reproduction, because he is at present in service, could not be an active member of the committee, but he was able to get leave and to sit in on all its meetings, so that it had the benefit of his invaluable experience in its discussions of technical phases of the microcard problem.

Prior to its first meeting all members of the committee had been supplied with copies of some formidable agenda, and, although few of the items on it survived the committee's three solid days of discussion in the form in which they appeared in it, most of them did manage to survive. Because of lack of time at this first meeting to cover so much ground, all that voluminous portion of the agenda dealing with the "division-of-fields" aspect of microcarding was postponed for later consideration.

The committee did, however, in its first three days' meeting, accomplish a great deal. It formally organized itself, agreed as to the scope of its own duties, set limits to its powers and responsibilities, and outlined procedures to govern its sessions. It adopted carefully framed rules establishing exact physical and bibliographical standards for microcards. It agreed on a subject heading code for them. It set up a standardized microtext and a standardized 
printing format for the backs and fronts respectively. It drafted rules for microcard cataloging analysis.

These were all essential first steps if the ideal is to become a reality to which we all look forward, viz., to have microcards which, regardless of their source, will be automatically interfilable. But the committee, at its first meeting, did still more. For the larger part of two sessions, for example, it discussed the basic question: What ought to be the fundamental organization of microcard production? And, although here it did not attempt to lay down any specific rules or even to make any definite recommendations, it did adopt one very important "expression of opinion" and it did greatly clarify the various problems involved in the minds of the committee's own members. To this aspect of the committee's initial deliberations I shall wish to devote the concluding portion of this paper.

One fact about the committee's first meeting deserves comment. In its three days it passed some forty-odd separate formal resolutions. Practically every one of these resolutions, when it was first presented, met with a sharp barrage of criticism and proposed amendment. But throughout all the committee's meetings there was evident a sincere desire on the part of all its members to reach common ground, and the proof of this desire is that the committee found itself able to adopt all but three of its resolutions unanimously.

It cannot be too often emphasized, however, that the Microcard Committee deems itself an advisory one only. And, in consonance with this concept of its powers, when it shall have finally approved its "Microcard Code," it proposes to have this printed in some form that will enable librarians everywhere to examine it, to comment upon it, and to criticize it. And the committee does not intend even to recommend it as a code until the sifted result of all the various comments and criticisms it may receive have had its very careful consideration.

\section{Patenting and Trade-Marking of Microcards}

I feel I should make a word of personal comment on one action which was taken by the committee. The Scholar ... said: $:^{5}$ "Microcards are not patented. It is quite possible that no patent protection upon them could have been secured; but, in any event, no effort was made to get any. Because they are not protected by patent, the library world has no legal control of any sort over them. Anyone can make them, use them, buy them, sell them."

But Lt. Tate pointed out, at one of the first sessions of the committee, that this complete lack of control in itself has dangers. As a matter of fact, he strongly urged that steps be taken to acquire some sort of protection for microcards and warned that my very desire not to attempt any personal control over their development gave unscrupulous commercial interests possible opportunity to step in and, perhaps, to some degree at least, to deprive libraries of that control. In the discussion that followed it was made clear that, although this was not a possible danger from a patent standpoint (beeause the microcard idea had been definitely put in the public domain), it was still a possible danger so far as the coined word "microcard" was concerned. It was argued that someone might take this word, might apply it to some sort of a microprint which was not a microcard at all, and might then try to estop the library world from using it for microcards-causing confusion and trouble, if nothing more.

The committee then asked me if I objected to trademarking the term. I said "No," provided it was clearly understood

${ }^{5}$ Rider, op. cit., p. 190. 
that I might assign the microcard trademark, if and when it was secured, to the committee, or to some other library body, for it to hold, in escrow as it were, for the good of the library world as a whole. With this understanding, trademark protection for "microcards" has been obtained.

\section{Centralization vs. Decentralization of Production}

When we ask, what is, from a library standpoint, the basic organization on which microcard production ought to proceed? we really seek answers to three main questions:

1. Should the issuance of microcards be centralized or decentralized?

2. Should microcard issuance be carried on cooperatively (i.e., either by the libraries themselves or by a central agency, or agencies, working for them) or commercially (as book publishing is now being done) or both?

3. Should there be attempted some plan for world-wide interlibrary cooperation in microcard issuance (each country, for example, being held primarily responsible for its own publishing output); or should such a plan as this be dismissed as mere wishful thinking, as a pleasant dream in international comity, and should we, in place of it, lay out a plan for the United States alone to plunge ahead, as best it can, with the world as its microcard province, and burden?

Now these three questions - and there are a number of subsidiary ones-are not theoretical ones; they are intensely practical. We have available in microcards an entirely new publishing technique. As librarians we have, to a very considerable degree, oppor- tunity to say how that technique shall be utilized. And so, now, before microcard development gets beyond our grasp, it would seem to be very much worth our collective while to study this problem of basic organization and to endeavor to see which, out of all possible microcard publishing methods, are most likely to serve our libraries and our scholars most efficiently.

Nor does the "we" who should do this studying mean the Microcard Committee alone. It is the library world as a whole that must, in the last analysis, do the deciding. And meanwhile, before it even recommends, the committee will most sincerely welcome all the light it can get from any source and any pertinent comment from any librarian who has given the above three questions thought.

From the two lengthy sessions which the committee, at its recent first meeting, spent in the consideration of the first two of these three basic questions (the third, it will be remembered, was laid on the table) one resolution of significance emerged, of significance both in its scope and in the fact that it was unanimously adopted. It concerned the question of centralization vs. decentralization of production. The Scholar $\ldots$, it will be remembered, said :

There will be those who will believe that the publishing of microcards might be done most effectively by some sort of single great central organization. It is only, they will say, by such a centralized handling of the cataloging, filming, printing, and distributing of them that it will be possible to secure that uniformity of format and subject headings, and that scholarly adequacy, accuracy, and comprehensiveness that are admittedly essential. The force of some of their arguments cannot be denied. But there are also difficulties in the way of such a centralization, difficulties that would seem to be too real and too strong to be effectively overcome.

The main one is this: behind every microcard there must be, not merely an original copy - and in most cases several original copies - of the book copied; there must also be behind it, at the constant call of its makers, all its background literature, i.e., a library in its subject field. Every cataloger knows that, properly to catalog and abstract one book, it is often necessary to consult ten related books. In other words, before any centralized microcard publishing organization could even start 
to do its work it would have to build up for itself an enormous centralized library. And "enormous" would be no mere rhetorical phrase, for this organization would be proposing to reproduce by means of microcards the research materials of every subject field, every discipline, every profession, and every social interest. The building up of such a new library as this would be neither practicable nor practical.

Instead of such a central microcard library and issuing agency, which would be bound, to a very great extent, to duplicate already existing library facilities, besides presenting political and administrative problems of the first order, it would seem better, from every angle, to decentralize the project and to build upon the excellent foundations that already exist in our various research libraries. . ..$^{6}$

The three paragraphs above were quoted in the committee's agenda to furnish a starting point for its discussion. And, continuing, the agenda said:

When we attempt to analyze our basic problem we find that microcard production clearly separates itself into work upon four levels or stages, each one quite different in character from the others, and so involving its own special set of problems. Some of these levels seem to lend themselves to commercialization; some pretty clearly do not. With some, centralization of effort seems, theoretically at least, to be possible, or even desirable. These four levels are:

I. The gathering together and the physical organization into what we call a library (or libraries) of the book, periodical, document, map, picture, music, and manuscript materials which are going to be subject to microcarding

2. The bibliographical organization of this mass of diverse materials, i.e., what we librarians term its cataloging (together with, in the case of microcards, its abstracting)

3. The making of microcards as a dual manufacturing process, i.e., the printing of the microtext on the back of the cards (either photographically or typographically, as the development of the techniques involved and the material being reproduced may dictate) and the printing of the catalog entry and abstract on their fronts. And, finally,

4. The distribution of these microcards to

${ }^{6}$ Rider, op. cit., p. $176-78$. library (and possibly to other) subscribers, large and small, the country over, or, perhaps, the world over.

This last is also, however, a dual process; it involves purely physical routines, such as card filing, sorting, "searching," packing, and shipping-routines which, although they are essentially simple, become complex as they grow in magnitude-and also "selling," i.e., the securing of global subscribers to, or of individual purchasers for, the microcards made.

Of these four levels, I certainly, and 2 almost as certainly, do not invite commercial exploitation. In other words, commercialization appears likely only upon levels 3 and 4 and there probably only in certain fields such as law and medicine.

But what of centralization? Theoretically it is clearly possible for centralization of effort to begin at any one of these four levels. But what of practicality rather than theory? To clarify our thinking, let us see how far each of us can agree with the following tentative theses:

a. Complete centralization of all microcard making at one point (i.e., beginning at level $I$ and continuing through levels 2,3 , and 4 ) would unquestionably be ideal so far as assurance of uniformity of result, surety of unduplicated coverage, and net efficiency of operation are concerned.

b. But such a completely centralized effort as this, no matter how relatively modest it might be at the start, would clearly have to envisage an ultimate capital investment running into a great many millions of dollars and would involve wide areas of duplication in collecting with already established libraries

c. Centralization beginning at level 2 would enormously reduce the capital investment required, would eliminate the duplication in book collecting, and would retain substantially all the advantages of centralization

d. Even this much centralization would, however, necessitate an ultimate plant investment running into millions and a staff running into thousands. While, by American 
business standards, such an operation would not be even importantly large, it would be, bibliographically speaking, quite unprecedented and would require the solution of a number of bibliographical and administrative problems of the most discouraging complexity ${ }^{7}$

e. If centralization of levels 2,3 , and 4 were effected, the work of the cooperating libraries would be limited to sending in to the central agency two copies of all items to be microcarded. (Or one copy, as per comment above.)

f. It would be possible to centralize levels 3 and 4 only, the cooperating libraries in this case cataloging and abstracting their items for microcarding, and sending in cataloging "copy" for them, along with their two copies (or one copy) of each item. It seems, however, to be the general concensus among catalogers who have had experience in cooperative cataloging, that cataloging codes and rules alone, no matter how much they may be detailed, are not sufficient to effect the required degree of uniformity of bibliographical result if cataloging has been done in many different places. On the other hand, they do seem to agree that this required degree of uniformity can be attained if there is at the central agency a relatively small cataloging staff to check and coordinate the cataloging copy received from these many sources

g. It would be possible to centralize level 3 only, returning all cards made to the cooperating libraries for them to distribute. On the other hand, libraries are not equipped to handle card distribution on a large scale, while any one ordering microcards would very much prefer to be able to send all orders to one distribution point rather than to a hundred points

h. Centralization of level 3 (i.e., the physical making, or manufacturing, of the cards) seems to meet with almost unanimous library approval. And this is easy to understand. A plant fully equipped to print both sides of microcards, operating on a commercial scale, would require a minimum investment of somewhere between thirty and sixty thousand dollars and a staff of from ten to twenty persons. Few libraries have any desire to em-

\footnotetext{
"The "division-of-fields" portion alone of the committee's agenda drafted about thirty rules charting a course through this one particular maze, and even these rules were admittedly only first steps for this portion.
}

bark upon so substantial an operation outside of their usual routines. Furthermore, few of them could provide, of themselves, the microcard output required to keep even a minimumsized plant such as this busy. An even larger plant would enable mass production methods to be introduced, which would effect further significant economies.

These eight theses summarize the discussions and the conclusions of the committee. As stated, at the end of them it unanimously adopted the resolution reprinted below. Although in the absence of funds, this resolution may be criticized as a pious hope, it indicates the lines along which microcard organization should, if possible, proceed.

The sentiment of this committee is in agreement with the conclusion reached on page 5 of the agenda, viz., that centralization of microcard production upon level I, i.e., the accumulation of materials for microcarding in a single central agency, is neither desirable nor practicable.

It believes, however, that the centralization of production upon levels 2, 3, and 4 (viz., cataloging, the physical making of the cards, and their distribution) is both practicable and desirable, if the funds necessary to finance such a centralization of effort can be obtained.

It believes furthermore that such a centralization of microcard production is cumulatively desirable, i.e., that it is most desirable at level 4 , next most desirable at level 3 , and next most desirable at level 2 . The economies in cost and the superior quality of service which centralization of production render possible are so significant and so substantial that we feel that, although any offer to provide funds to initiate microcard production, even though it be on only an experimental scale, should be welcomed, funds sufficient in size to initiate fully centralized effort upon one, or all, of the three levels mentioned are particularly to be desired, and to be sought after.

Admittedly all our present discussion is in the most tentative of general terms. It has to be. No one can set up, or recommend the setting up, of any sort of a microcard issuing organization without some 
objective data to work with. Sooner or later the committee-and that means the library world-will, we hope, be faced with, and will be required to express its preference between, definite microcarding proposals which have been submitted to it. Some may involve only one level; some, possibly, may compass all four. Some may appear to be practical, some impractical. Some may be large, even grandiose; some of them small, even trivial. Some of them may be wholly philanthropic in motive, some of them frankly commercial. But only with such definite proposals at hand will definite recommendations be possible.

\section{Crucial Point of the Issuing Problem}

In its resolution above, the committee specifically states that it considers centralization upon level 4, i.e., microcard distribution, even more desirable than card manufacturing centralization. Its reasons have already been suggested, but let us examine them further for a moment.

The Scholar . . . urged that microcards be sold by "global" subscription only. I have reluctantly come to the conclusion that this, however desirable, is impracticable. But, if we drop the global-sale-only idea, we have to face the necessity of building up enormous stocks of microcards (like the stock of the Card Division of the Library of Congress, for example) and the continual "searching" of these stocks to fill individual card orders. This sort of order work is highly specialized; it is the kind of operation in which large financial losses are easily possible; and it is a sort of administration with which most librarians have had no experience.

But there is another, and extremely important, angle to the distribution process; for distribution, in its physical aspects, is, it will be remembered, but the first part of level 4. There is a second part, i.e., selling, the finding of markets for the cards made. Whatever it may be called, however it may be disguised, selling is an unescapable part of the microcard issuing process. Unless adequate numbers of purchasers for all the microcards made are found, any production organization we may set up is going to collapse very quickly. This point was brought up in one of the Microcard Committee's sessions, but it was brought up toward the end and did not receive the discussion its importance deserved.

Unless I am mistaken, it is at this very point that we are going to find among libraries the greatest reluctance to assume responsibility. Or, to put the same statement the other way round, we are going to find at this point the most eager, and most nearly unanimous, willingness among them to have some central organization take over the administrative burden of producing microcards.

But it will require only a short consideration to reveal quite clearly that, just because this selling process is so crucial a one, any centralization of it is bound to work a farreaching change in the entire microcarding setup. Why? Because he who is made financially responsible for seeing that sales are made is inevitably going to insist upon having the power to decide what the products are that are placed in his hands for sale.

But if the choosing of the items which are to be microcarded is transferred to a "microcarding center," our basic situation is altered. If $i t$ is going to ask the cooperating libraries for the items that it wants to microcard, instead of their sending to it the items which they want to have microcarded, the central agency is forthwith no longer a service agency but a "publishing" -an initiating and risk-taking-body. The difference is at once a profound and an unescapable one. 